Portland State University

PDXScholar

\title{
The metabolic cost of behavioral thermoregulation of body temperature in the northern alligator lizard Gerrhonotus coeruleus, and how it affects the classical concept of eurythermality
}

James Dudley Campbell

Portland State University

Follow this and additional works at: https://pdxscholar.library.pdx.edu/open_access_etds

Part of the Animal Sciences Commons, Biology Commons, and the Physiology Commons Let us know how access to this document benefits you.

\section{Recommended Citation}

Campbell, James Dudley, "The metabolic cost of behavioral thermoregulation of body temperature in the northern alligator lizard Gerrhonotus coeruleus, and how it affects the classical concept of eurythermality" (1981). Dissertations and Theses. Paper 3150.

https://doi.org/10.15760/etd.3139

This Thesis is brought to you for free and open access. It has been accepted for inclusion in Dissertations and Theses by an authorized administrator of PDXScholar. Please contact us if we can make this document more accessible: pdxscholar@pdx.edu. 
AN ABSTRACT OF THE THESIS OF James Dudley Campbell for the Masters of Science in Biology presented January 15, 1981

Title: The Metabolic Cost of Behavioral Thermoregulation of Body Temperature in the Northern Alligator Lizard Gerrhonotus coeruleus, and How it Affects the Classical Concept of Eurythermality

APPROVED BY MEMBERS OF THE THESIS COMMITTEE:

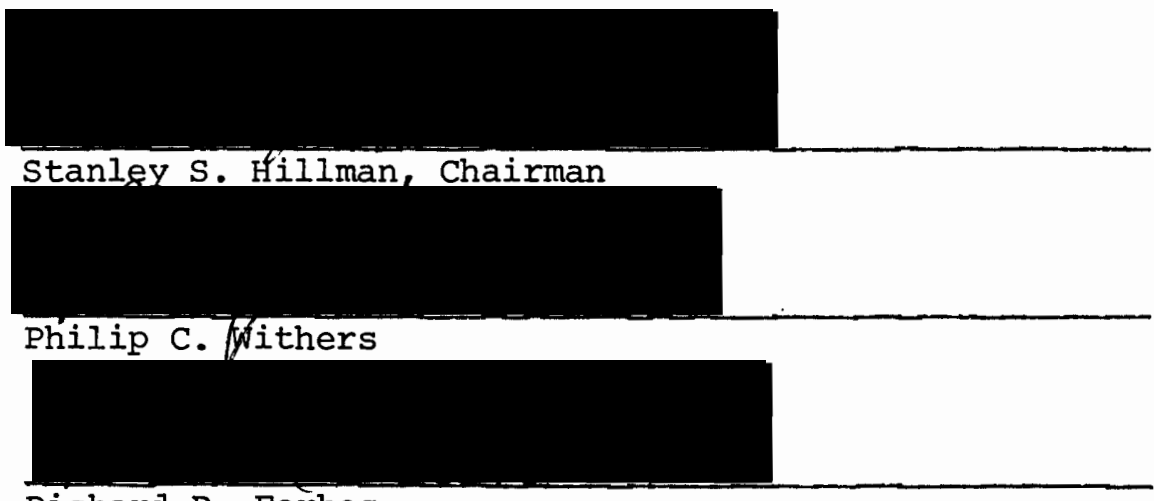

Richard B. Forbes

The effect of total metabolic cost expenditures on the precision of behavioral thermoregulation was investigated for the purportedly eurythermic Northern Alligator lizard (Gerrhonotus coeruleus). An operant apparatus was designed to test metabolic output at different heat reinforcement magnitudes. The mean $\mathrm{T}_{\mathrm{B}}$ reflected in each trial was positively correlated to the length of reinforcement. The shuttle rate during each trial was inversely correlated to the length of reinforcement. The standard deviation and total metabolic costs did not vary significantly between trials undertaken at the same ambient temperature. 
Eurythermality in $G$. coeruleus is caused by fluctuations in preferred body temperature and not byefluctuations around this temperature." The metabolic cost of behavioral thermoregulation did not change with corresponding changes in reinforcement magnitude. This indicates that eurythermality is the recorded effect of lizards behaviorally regulating to different $\mathrm{T}_{\mathrm{B}}$ in a stenothermic manner, rather than of random $T_{B}$ fluctuations in a wide range of normal activity (the classical view of eurythermality). 


\section{THE METABOLIC COST OF BEHAVIORAL THERMOREGULATION OF BODY TEMPERATURE IN THE NORTHERN ALIIGATOR LIZARD GERRHONOTUS COERULEUS, AND HOW IT AFFECTS THE CLASSICAL CONCEPT OF EURYTHERMALITY}

by

JAMES DUDLEY CAMPBELL

A thesis submitted in partial fulfillment of the requirements for the degree of

MASTER OF SCIENCE

in

BIOLOGY

Portland State University

1981 
TO THE OFFICE OF GRADUATE STUDIES AND RESEARCH:

The members of the Committee approve the thesis of James Dudley Campbell presented January 15, 1981.

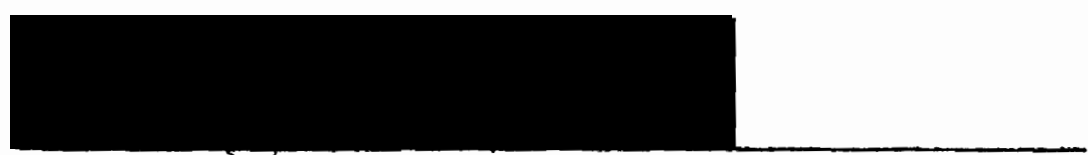

$$
\text { stanley S. Hillman, Chairman }
$$

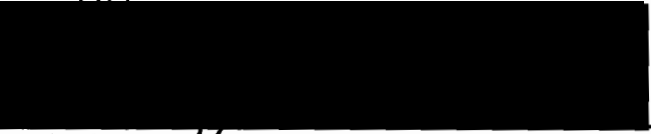

Philip C. Withers

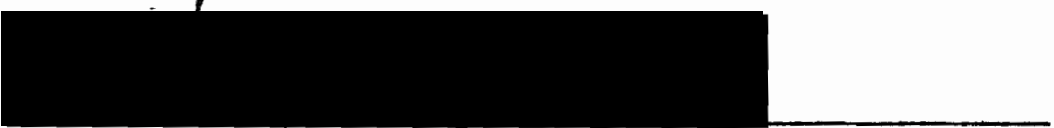

Richard B. Forbes

APPROVED:

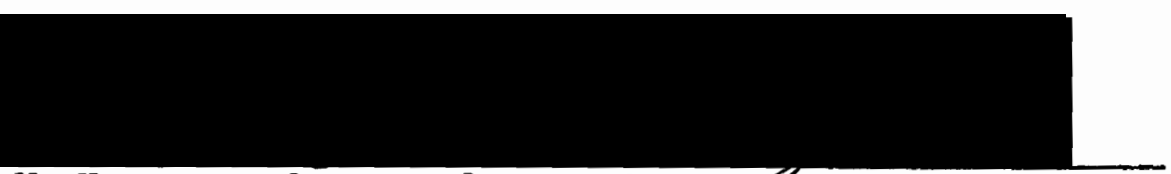

W. Herman Taylor, Head, Department Biology

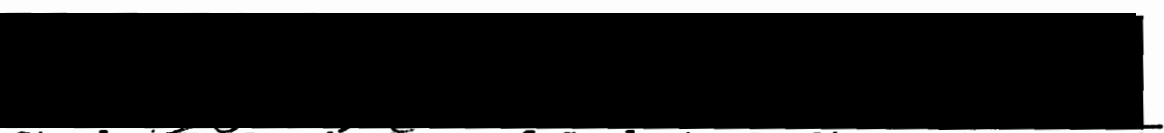

Stanley E. Rauch, Dean of Graduate Studies and Research 


\section{ACKNOWLEDGMENTS}

I would like to thank a number of people who made this study possible. I would first of all like to thank my advisor and friend Dr. Stan Hillman for his valuable insight, encouragement, and advice. I want to thank Dr. Phil Withers for the use of his microprocessor and the instruction on how to program it.

The members of my graduate committee, Dr. Stan Hillman, Dr. Phil Withers, and Dr. Dick Forbes were always open and receptive to my frequent inquiries. Dr. Larry Crawshaw contributed significantly to the design and implementation of this project.

I want to thank the many friends who helped along the way: Scott Landrey, Mike Andrews, Mitch Wolgamott, and Chris House for the hours and miles they spent helping me collect specimens, Bill and Harriet Hall for their friendship and support; and my family for their patience and support. 
TABLE OF CONTENTS

PAGE

ACKNOWLEDGMENTS . . . . . . . . . . . . . . . . . . . . iii IIST OF TABLES •. • . . . . . . . . . . . . . . • • • V

LIST OF FIGURES • • • • • • . . • • . • • • • • • • • • • vi vi

CHAPTER

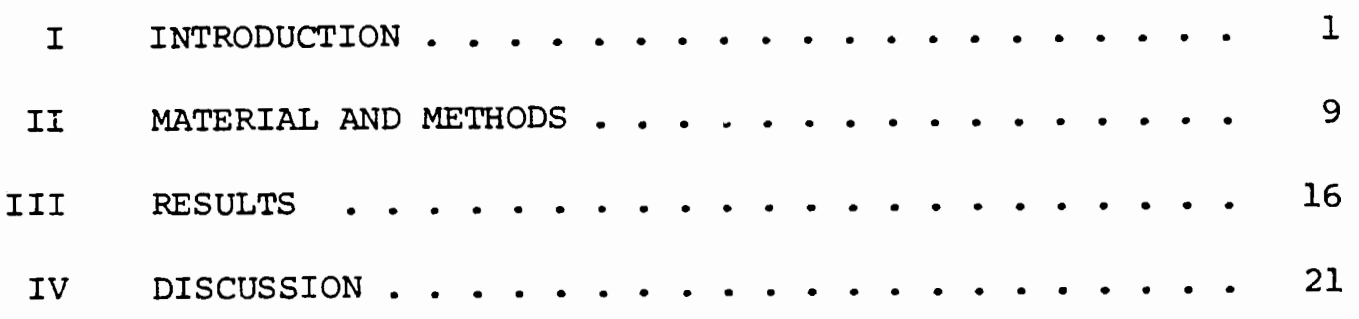

LITERATURE CITED . . . . . . . . . . . . . . • • 


\section{LIST OF TABIES}

TABLE

PAGE

I Sumnary of Mean Body Temperatures $\left(\overline{x T}_{B}\right)$, Mean Standard Deviations ( $\overline{X S D})$, Mean Shuttle Rate ( $\bar{x}$ Resp/Hr), Metabolic Rate Per Hour for Regulating Time Only $\left(\mathrm{VO}_{2}, \mathrm{Reg}\right)$, Metabolic Rate Per Hour for Entire 12 Hour Periods $\left(\dot{\mathrm{VO}}_{2}, \mathrm{Avg}\right)$, Metabolic Rate Per Hour for Entire 12 Hour Trials (Mass Specific $\dot{\mathrm{VO}}_{2}$, Avg), and Metabolic Rates Per Gram Per Hour for Regulating Time only (Mass Specific $\dot{\mathrm{VO}}_{2}, \mathrm{Reg}$ ), for Four Experimental Trials; Trial A $\left(10^{\circ} \mathrm{C} \mathrm{T}_{\mathrm{A}}\right.$ with a 45 Second Heat Reinforcement), Trial B $\left(10^{\circ} \mathrm{C} \mathrm{T}_{\mathrm{A}}\right.$ with a 90 Second Heat Reinforcement), Trial $\mathrm{C}\left(10^{\circ} \mathrm{C} \mathrm{T}_{\mathrm{A}}\right.$ With a 180 Second Heat Reinforcement), and Trial D $\left(20^{\circ} \mathrm{C} \mathrm{T}_{\mathrm{A}}\right.$ with an 180 second Heat Reinforcement). All Values are Mean \pm standard Deviations with the Number of Observations Indicated for Each Trial.. • 17

II Summary of Statistics for Least Squares Regression Analysis for Mass Specific Oxygen. Consumption rate for Lizards While Regulating, as a Function of Body Mass. ( $N=5$ for all Regressions). See Table I for Trial Legend. . . . . . . . . . . . 20 


\section{LIST OF FIGURES}

FIGURE

PAGE

1. Histogram of the Mass Specific $\dot{\mathrm{VO}}_{2}$, Reg and its Statistical

Metabolic Components . . . . . . . . . . . 25

2. Graph of Mass Specific $\dot{\mathrm{VO}}_{2}$, Reg Versus Mass for all

Trials . . . . . . . . . . . . . . . 31 


\section{CHAPTER I}

\section{INTRODUCTION}

The behavioral regulation of body temperature $\left(T_{B}\right)$ by lizards is a well known phenomenon. Lizards that normally maintain a very narrow range of $T_{B}$ during activity are considered stenothermic, lizards with a wide range in $\mathrm{T}_{B}$ during activity are eurythermic. Many animals are considered to be heliothermic, since they utilize radiant heat energy as a predominant source in the maintenance of a constant $T_{B} \cdot$ Other lizards are considered to be thigmothermic, because they utilize conductive heat gain from contact with the substrate. However, most lizards utilize both radiant and conductive heat gain (Soule' 1963). The behaviors involved in behavioral thermoregulation are intricate, and include changing the amount of body surface that is exposed to the sun's rays be altering the angle between the body axis and the sun (Heath, 1965; Bartholomew, 1966; Bartlett and Gates, 1967; Delvitt, 1971; Muth, 1977), increasing or decreasing conductive heat losses by moving to warmer or colder substrates (Heath, 1965; Hammel et al, 1967; Weathers, 1970; Spellerburg, 1972), postural changes that minimize or maximize contact with conductive surfaces (Heath, 1964; Bartholomew, 1966; DeWitt, 1971; Muth, 1977), the utilization of panting (Ruibal, 1961; Case, 1972), and retreat to cooler subterranean or arboreal areas (Norris, 1948; Heath, 1964; Pianka and Parker, 1972; Muth, 1977). Control of heat flux is also possible through vasomotor responses 
(Bartholomew and Tucker, 1963; Weathers, 1971; Morgareidge and White, 1969; White, 1973), and by temporal regulation of activity bouts (Schmidt-Nielsen and Dawson, 1964; Heatwole et al, 1969; Porter et al, 1973; Huey, 1974b) .

The optimum $T_{B}$ for many reptilian physiological processes occurs within the normal activity range of $T_{B}$, particularly for stenothermic species (Dawson, 1967). The ability to maintain $T_{B}$ within this range and avoid body temperature extremes at either end of the preferred range is a major evolutionary adaptation in reptiles (e.g., Bogert, 1949). The lizard can optimize many physiological processes by maintaining $T_{B}$ within the normal activity range and close to the preferred body temperature (PBT). However, this homeostatic advantage is counterbalanced by the metabolic cost of thermoregulation. Any deviation in $\mathrm{T}_{\mathrm{B}}$ from the preferred range should require an energy expenditure to return $\mathrm{T}_{\mathrm{B}}$ to the preferred level.

Huey (1974a) studied the effect of habitat type on precision of thermoregulation and TB for Anolis cristatellus in two adjacent habitats. He introduced a "cost of thermoregulation" factor into his analysis be measuring the distance that a lizard had to shuttle from a perch to sun. The distance between basking sites of forest-habitat lizards was significantly greater than that of open park lizards. Huey (1974a) therefore inferred that the cost of thermoregulation would be greater in the forest habitat. In fact, the $T_{B}$ of the forest lizards were found to correlate closely with ambient temperature $\left(T_{A}\right)$ and there was a wider $\mathrm{T}_{\mathrm{B}}$ range for normal activity. The open-park lizards were found to be heliothermic with a narrower normal activity range; i.e., 
they showed greater precision in regulating $T_{B}$. It was therefore apparent that Anolis cristatellus regulated $\mathrm{T}_{\mathrm{B}}$ only in the open-park areas, presumably because the cost/benefit ratio was more favorable. Huey and Slatkin (1976) suggested that an increase in available productivity in a given habitat would lead to more precise thermoregulation. Higher productivity in this case is defined as additional benefits in food aquisition with little or no added cost. If food is readily available a lizard will spend less time searching for food (Iow temporal cost) and will therefore have more time and energy available for thermoregulation. There might be a tradeoff for lizards between the time spent thermoregulating and foraging in an environment where the lizard has to spend the majority of its time searching for food. The tradeoff should result in a decrease in $T_{B}$ or precision of regulation, and might be reflected by a poorer nutritional state e.g., a decrease in percentage of body fat, if food acquision was significantly curtailed.

Lee (1980) used length-specific fat body weights as an index to a lizard's ability to gather and process available food. He assumed that fat, well-fed lizards react to their environment as though it were highIy productive, whereas poorly-fed lizards react to their environment as though it were of low productivity. He reported that the relationship of environmental productivity to thermoregulatory precision or mean $T_{B}$ of Anolis sagrei was positively correlated for open (sunny) versus closed (shady) habitats. This supports Huey and slatkin's (1976) contention that lizards thermoregulate precisely only in those environments where food is readily available. 
A study of Anolis oculatus on the island of Dominica (Ruibal and Philibosian, 1970) suggested that the eurythermal pattern of $T_{B}$ for this species may have evolved in response to the absence of competition (ecological release). Huey and Webster (1975) suggest that eurythermy in Anolis is related to their evolutionary origins in moist tropical forests. The environmental constraints of such habitats to behavioral thermoregulation favor thermal passivity to $T_{A^{\prime}}$ and hence eurythermality.

Various researchers have examined the field $\mathrm{T}_{\mathrm{B}}$ of lizards as they relate to habitat (see Brattstrom, 1965, for a detailed list). The PBT over which lizards are active are known for many species. However, such studies often do not necessarily address the question of whether there are genetic differences in thermoregulation between various species. For example, because of greater surface area to volume ratios smaller species equilibrate thermally with their environment at a faster rate than larger species, so it is more difficult for small species to maintain an elevated $\mathrm{T}_{\mathrm{B}}$. Furthermore, field $\mathrm{T}_{\mathrm{B}}$ data may also reflect differences in habitat temperature profiles and not necessarily genetic differences of lizard species. That is, the environment may be eurythermal so the lizard is also eurythermal, even though the lizard is really not different in thermoregulatory capabilities from so called stenothermic species from stenothermic environments.

Many authors (see Berk and Heath, 1975, for a recent review) have tested lizards in a temperature gradient in the laboratory and found that the temperatures selected are often significantly higher than PBT for the same species in the field. There are also data which 
suggests that photoperiodicity (Ballinger et al. 1969) and feeding schedules (Regal, 1966; Hoffman, 1973) may alter PBT in lizards. Huey and Slatkin (1976) suggest that competition for resources and risk of predation may alter PBT. Lizards may also regulate differently between separated high and low set points (Barber and Crawford, 1976, 1978). None of the above authors assessed quantitatively the metabolic cost of thermoregulation. Thermal gradients demand virtually no thermoregulatory effort by the lizard, and therefore are no-cost environments, obviously not comparable to a real environmental situation.

One way to assess the cost of thermoregulation in the laboratory is to use an operant conditioning paradigm where the cost of shuttling can be calculated. Burghardt (1977) reviewed the literature on operant conditioning of reptiles in a laboratory environment. The reinforcements used in conditioning mammals are usually related to hunger, thirst or reproductive drives. The low caloric intake of food by reptiles precludes using the hunger drive as a reinforcement in the operant conditioning. However, exogenous heat provides a useful reinforcement for conditioning reptiles.

Rozin and Mayer (1961) conditioned goldfish in an aquarium of hot water to press a disc and thereby regulate the temperature of water in the aquarium by rewarding the disc press with a reinforcement of cold water. The fish effectively regulated their $T_{B}$ by increasing or decreasing the disc press response rate. This experiment demonstrated that ectotherms would respond operantly to regulate their $T_{B}$. Heat avoidance by disc pressing was also used by Kemp (1969) as an operant 
technique to study the thermoregulatory behavior of the Desert Iguana, Dipsosaurus dorsalis. This was the first recorded experiment using heat reinforcement to study the behavioral thermoregulation of a lizard.

Kellogg and Pomeroy (1936) trained water snakes (Tropidonotus fasciatus) to negotiate a maze, using heat (warm water) as a reinforcement.

Regal (1971) also used an operant technique to study the thermoregulatory behavior of the Island spectacled Lizard (Klauberina riversiana), but he used the onset of heat as the reinforcer instead of the heat avoidance method utilized by Kemp (1969) .

Richardson and Brown $(1975,1976)$ also used the onset of heat as a reinforcement in the operant conditioning of Dipsosaurus dorsalis and the Collared Lizard (Crotaphytus collaris). They found that other paradigms of operant techniques, such as fixed ratio schedules of reinforcement (i.e., the animal is reinforced only every second, third, fourth,......etc, response instead of every response) did not work for studies of behavioral thermoregulation. The same conclusion was reached earlier by crawford et al, (1968) in their study on the effect of fixed ratio reinforcements to response rates in turtles. Both studies showed that a continous reinforcement schedule was the best way to study selective thermoregulatory behaviors in reptiles.

In experiments with Sprague-Dawley rats and Squirrel Monkeys, Carlisle (1969) found that endotherms in a cold environment would respond to heat reinforcements at a level sufficient to ensure homeostasis only if the reinforcements were continuous. The animals 
failed to thermoregulate behaviorally at a level sufficient to ensure homeostatis during trials using ratio schedules.

Although reinforcement schedules of the variable or fixed (F2 or greater) ratio do not increase the frequency of response, the magnitude or reinforcement does. Weiss and Laties (1960) found that variations in heat source intensity or longevity inversely affect the response rate of lever pressing by rats for thermal reinforcement.

Reptiles are easy to shape for operant experiments (Burghardt, 1977) and may require little or no shaping when the operants are simple (Linton, 1976). Experiments in operant conditioning using heat reinforcements have shown that reptiles quickly learn simple operants, exhibit the desired operant regularly with continous reinforcements, and will change the response rate if the magnitude (length or strength) of the reinforcement is changed.

The experimental apparatus used here is a thermoregulatory system in which the energetic cost of thermoregulation and ambient temperature can be modified experimentally. This system is essentially a shuttle apparatus with heat lamps at either end. The lizard, by shuttling to one end of the box, triggers a switch at that end (by gravity) which turns on the heat lamp. There is a preset time interval for the lamp to remain on (from $0-240$ seconds), and at the termination of this interval the lamp turns off. In order to reactivate a heat lamp, the lizard must move to the other lamp at the opposite end of the box so as to turn that lamp on for the same preset time interval. Therefore, the lizard must move a known distance (at a predictable metabolic cost) in order to procure the radiant heat energy needed to elevate and regulate 
$T_{B}$. By varying the length of time that the lights remain on, it is possible to force the lizard to shuttle more or less frequently, thereby forcing the lizard to expend more or less energy in order to thermoregulate. The shuttle box apparatus is maintained in a constant temperature cabinet, so that $\mathrm{T}_{\mathrm{A}^{\prime}}$ the thermal gradient that the lizard works against, is varied; this also alters the cost required for behavioral thermoregulation. When the cost of thermoregulation becomes too great (light on for short interval and/or low ambient temperature), or the $\mathrm{T}_{\mathrm{A}}$ becomes to high, the lizard would be expected to cease behavioral thermoregulation.

The physical habitat diversity (Stebbins, 1966; Vitt, 1974) of Gerrhonotus coeruleus and its reported passivity to a wide range of environmental temperatures (Brattstrom, 1965; Vitt, 1974) make this lizard a good subject for the study of eurythermality. 


\section{CHAPTER II}

\section{MATERIAIS AND METHODS}

\section{Experimental Animals}

Northern Alligator Lizards (Gerrhonotus coeruleus) were collected in June 1979, between Reedsport and Drain, in Douglas County, Oregon. All healthy adults found at this location were collected and returned to the $1 \mathrm{ab}$.

The lizards were kept in an Environator Model I-3236 environmental chamber at $20^{\circ} \mathrm{C}$, with lights on from 9:00 a.m. until 9:00 p.m. The lizards were fed mealworms and crickets and given water ad lib.

Five female lizards (mean mass $10.2 \pm 2.6 \mathrm{~g}$, range 6.6 to $14.4 \mathrm{~g}$ ) were placed in individual cages within the environmental chamber.

\section{Operant Apparatus}

An enclosure $1 \mathrm{~m}$ long, $23 \mathrm{~cm}$ high and $23 \mathrm{~cm}$ wide was constructed with a bottom of styrofoam and sides of plastic covered with duct tape. a $5 \mathrm{~cm}$ lip encircled the otherwise open top to prevent lizards from climbing out. White styrofoam was used on the bottom because it reflected light and therefore did not store much heat from the lamps. The plastic sides and Iip were covered with duct tape to prevent melting or ignition from the heat lamps.

The entire enclosure was balanced on a fulcrum such that a weight of $1 \mathrm{~g}$ at either end would tip the enclosure in that direction. Two 8PK-8246-8FY (Microswitch) sealed, metal clad proximity microswitches 
were incorporated at each end of the balanced enclosure in such a manner that a tilt of $2 \mathrm{~cm}$ would close the switch circuit and register an electronic response.

Two sylvania 250 watt infrared heat lamps were suspended $33 \mathrm{~cm}$ above the ends of the balanced enclosure in such a manner as to provide radiant heat energy when turned on to the last $10 \mathrm{~cm}$ of the enclosure. A lizard seeking heat influx would have to walk to the very far ends of the balance enclosure.

A General Electric 25 watt bulb was wired in series with each heat lamp and inserted in a plastic tube with a photocell. An operant response from the lizard that turned on a heat lamp also turned on the 25 watt bulb in series, which in turn illuminated the photocell and produced a small voltage. This small voltage was detected by the microprocessor or millivolt recorder as an operant response on that end of the shuttle apparatus.

The entire operant apparatus was placed into an environmental chamber (Environator model 3486AL) and kept at a constant $\mathrm{T}_{\mathrm{A}}$. The environmental chamber containing the balanced enclosure was illuminated by 4 Sylvania 72 inch Coal white F72112-CW-VHO flourescent bulbs suspended 85 centimeters above the shuttle box.

The $T_{A}$ of the inside of the environmental chamber and the $T_{B}$ of the lizard were monitored using 30 gauge thermocouple wire and Omega thermal reference junctions. The $T_{A}$ thermocouple was placed in the enviromental chamber so that it was out of any drafts and away from possible radiant influence of the heat lamps. The temperature of the environmental chamber $\left(\mathrm{T}_{A}\right)$ was not changed appreciably by the operant 
apparatus. The $\mathrm{T}_{\mathrm{A}}$ always remained a constant $10^{\circ} \mathrm{C} \pm \mathrm{I}^{\circ} \mathrm{C}$ (trials $\mathrm{A}, \mathrm{B}$, and $\mathrm{C})$ or $20^{\circ} \mathrm{C} \pm I^{\circ} \mathrm{C}$ (trial D). The thermocouple used to monitor $\mathrm{T}_{\mathrm{B}}$ was inserted through the cloaca and into the small intestine and taped to the lizards' tail.

The electronic circuit for turning the heat lamp on and off at the proper moment and for the proper time sequence was designed using transistor-transistor-logic.

The $T_{B}, T_{A}$, and responses (activation of heat lamps from shuttling) were monitored using an Aim model 65 microprocessor or a Leeds and Northrup 12 channel multiplex recorder. Every six seconds the microprocessor measured $T_{B}$ from the thermocouple inserted in the lizard's small intestine. At 5-min intervals, the mean of the previous $50 \mathrm{~T}_{\mathrm{B}}$ values $(6 \mathrm{sec} \times 50=5 \mathrm{~min})$ were accumulated and averaged. At the end of each hour, the mean, variance, standard deviation and standard error of the $125-\mathrm{min} \mathrm{T}_{\mathrm{B}}$ average readings were calculated. The microprocessor simultaneously monitored the activity of the lizard (i.e., when and how many times it shuttled from end to end. The mean, standard deviation, variance, and standard error of the twelve hourly means were computed. The same information was obtained manually from the multiplex recorder.

The 5 lizards used in this experiment were introduced individually to the balanced enclosure while it was in the environmental chamber at $10^{\circ} \mathrm{C}$. The lizards were given 1 12-hr period 19:00 a.m. to 9:00 p.m.) to orient to the experimental apparatus. Gleeson (1979) found that Western Fence Lizards (Sceloporus occidentalis) became familiar with an experimental apparatus after a single exposure and 
required no further training period. The behavior of the $\mathrm{G}$. coeruleus used in the baseline studies supported this conclusion. The day following enclosure orientation, operant conditioning was started.

The lizards were shaped, using standard operant conditioning techniques, to walk back and forth in the balanced enclosure. Shaping reinforcements were provided when the lizard moved towards the far end of the balanced enclosure. Using the principle of successive approximations to desired response, the lizards had to move progressively closer to the other end of the balanced enclosure in order to be heat reinforced. Eventually the animals were walking along the balanced enclosure far enough to tip it in the opposite direction and activate the proximity switch, at which time the heat lamp immediately above that switch (and the animal) would turn on for the prescribed length of time and reinforce that animal with heat. Shaping time varied from 5 minutes to 45 minutes. The animals were considered to have reached the shaping criterian when thay had a relatively constant temperature $\left( \pm 3^{\circ} \mathrm{C}\right)$ while regulating for at least 6 hours continously. The cessation of thermoregulation was considered to be the point at which $T_{B}$ was equal to $T_{A}$ and no further activity took place. Using this operant apparatus the following trials were run. Lizards number $1,2,3$ were run at $10^{\circ} \mathrm{C}$ with 90 second heat reinforcements for 5 trials each (preliminary trials); Lizards number $1,2,3$, 4 , and 5 were run at $10^{\circ} \mathrm{C}$ with 45 second heat reinforcements for 5 trials each (trial A); $10^{\circ} \mathrm{C}$, with 90 second heat reinforcements for 3 trials each (trial B); $10^{\circ} \mathrm{C}$, with 180 second heat reinforcements for 3 trials each (trial $\mathrm{C}$ ); and $20^{\circ} \mathrm{C}$, with 180 second heat reinforcements 
for 3 trials each (trial D). There was no statistical difference between the data from the preliminary trial and the data from trial B (both run at $10^{\circ} \mathrm{C}$ with 90 second heat reinforcements). Therefore, there was no apparent ordering effect observed. The data from trial B was used for comparison purposes in the results because all five lizards were represented in trial B as compared to only three lizards in the preliminary trial.

\section{STATISTICAI COMPUTATIONS}

Mean Body Temperature $\left(\overline{x T}_{B}\right)$

The mean body temperature for any given trial was computed by taking the mean of all the hourly temperatures, during the entire trial sequence, when the lizard was actively thermoregulating (i.e., shuttling).

Shuttle Rates (resp/hr)

The shuttle rate in responses per hour was calculated by adding all the responses for a given trial period, divided by the number of hours the lizard actively thermoregulated during that trial.

Mean Standard Deviation ( $\overline{x S D})$

Mean standard deviations for any given trial period were computed by taking the mean of the standard deviations for those hours, during the entire trial period when the lizard was actively thermoregulating.

Cost $\left(\dot{\mathrm{VO}}_{2}\right)$

The cost in $\dot{\mathrm{VO}}_{2}$ was calculated in all cases by adding the metabolic cost of having an elevated $\mathrm{T}_{\mathrm{B}}$ during behavioral thermo- 
regulation to the energetic cost of moving from one end of the balanced enclosure to the other.

The mean metabolic cost per hour of maintaining $T_{B}$ at any particular temperature was calculated using the data of Hoffman (1973) for the Southern Alligator Lizard (Gerrhonotus multicarinatus webbi).

The metabolic cost of shuttling was calculated using the data of Schmidt-Nielsen (1972) for mammals. Lizards and mammals of the same weight have similar energy expenditures (Bakker, 1972). At speeds less than $1.1 \mathrm{~km} / \mathrm{hr}$, the energy cost of running for lizards is independent of body temperature (Dmi'el and Rappeport, 1976). All speeds in these experiments were far below this level.

\section{VO $_{2}$ While Regulating ( $\dot{\mathrm{VO}}_{2}$, reg)}

The mean cost in $\mathrm{VO}_{2}$ for those portions of the 12-hr trials when active behavioral regulation was taking place was calculated by adding the cost of maintaining the mean body temperature during hours of regulation to the metabolic cost of the total number of responses, divided by the hours spent regulating. The mean cost of thermoregulating in $\dot{\mathrm{VO}}_{2}$ per $\mathrm{g}$ for those parts of the $12 \mathrm{hr}$ periods when the lizards were actively behaviorly thermoregulating was calculated by dividing $\dot{\mathrm{VO}}_{2}$ regulating by the mass of the lizard (mass specific $\mathrm{VO}_{2}$, reg).

\section{$\dot{\mathrm{VO}}_{2}$ Average ( $\dot{\mathrm{V}}_{2}$, avg)}

The mean cost in $\dot{\mathrm{VO}}_{2}$ was computed for each entire 12-hr trial by taking the metabolic cost of shuttling and the metabolic cost of maintaining $\mathrm{T}_{\mathrm{B}}$ during periods of active regulating, and adding this to 
the metabolic expenditures during those hours when $T_{B}$ equalled $T_{A}$, divided by 12 to give $\dot{\mathrm{VO}}_{2}$ based on each entire 12 -hr period. The mean cost of thermoregulating in $\dot{\mathrm{VO}}_{2}$ per gram for each entire 12-hr period was calculated by dividing $\dot{\mathrm{vO}}_{2}$ average by the mass of the lizard (Mass specific $\dot{\mathrm{VO}}_{2}$, avg).

Scaling

A least-squares regression was computed for the mass specific $\dot{\mathrm{VO}}_{2}$ regulating for trails A through D. A probability of less than .05 (P .05) was considered significant. A t-test for slope and intercept was used to see if they were significantly different from 0 and to test if the slope was significantly different from the expected value for mass versus mass specific metabolic rate (slope of -.25).

\section{Statistics}

An analysis of variance with Bartlett's test for homogeneity of variance was used to determine if various parameters (e.g., response rate, $\bar{x}_{B^{\prime}}$, etc.) were significantly different for any trial (snedecor, 1956). A probability level of less than .05 ( $\mathrm{P} .05$ ) was considered significant if the corresponding $x^{2}$ (Chi-square) value for Bartlett's test was not significant. 
CHAPTER III

RESULTS

The accumulated data for trials A, B, C, and D were analyzed in three ways. Those trials at $10^{\circ} \mathrm{C}$ (trials $\mathrm{A}, \mathrm{B}$, and $\mathrm{C}$ ) were compared to each other. The trials run at $10^{\circ} \mathrm{C}$ were compared to trials run at $20^{\circ} \mathrm{C}$ (trial D). Finally a comparison was made between the trials at $10^{\circ} \mathrm{C}$ and $20^{\circ} \mathrm{C}$ where the reinforcement periods were both 180 seconds (trial $C$ versus $D$ ).

Mean Body Temperature $\left(\overline{x T}_{B}\right)$

The values for mean body temperature for each trial are shown in Table $I\left(\overline{x T}_{B}\right)$. The $\overline{x T}_{B}$ for trials $A, B$, and $C$ were significantly different $(P .01)$ as were $\overline{x T}{ }_{B}$ for trials $A, B, C$, and $D(P .001)$, and $\bar{x} T_{B}$ for trials $C$ and $D(P \quad .05)$. These data indicate that $\overline{x T}_{B}$ varies if reinforcement time or $\mathrm{T}_{\mathrm{A}}$ is changed.

Shuttle Rate ( $\bar{x}$ resp/hr)

The values for the mean shuttle rate for each trial are shown in Table I $(\bar{x} r e s p / h r)$. The $\bar{x}$ resp/hr for trials $A, B$, and $C$ were significantly different $(P .01)$, as were the $\bar{x}$ resp/hr for trials $\mathrm{A}, \mathrm{B}, \mathrm{C}$, and $\mathrm{D}(\mathrm{P}, .001)$. The $\overline{\mathrm{x}} \mathrm{resp} / \mathrm{hr}$ for trials $\mathrm{C}$ and $\mathrm{D}$ are not significantly different. These data indicate that the shuttle rate varies if the reinforcement time varies, but is not affected by changes in $\mathrm{T}_{\mathrm{A}}$. 


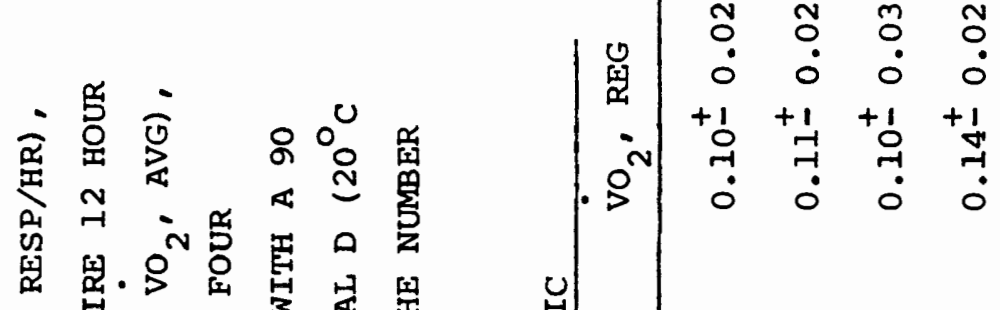

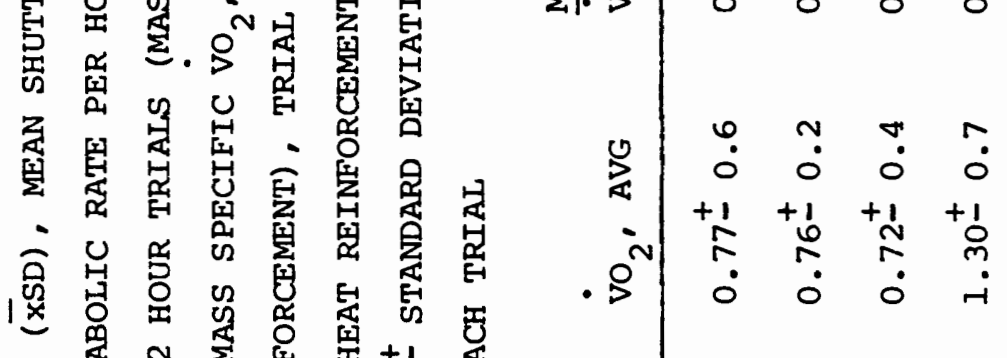

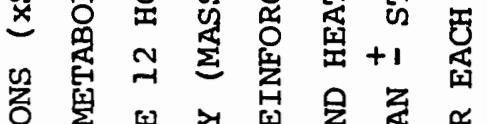

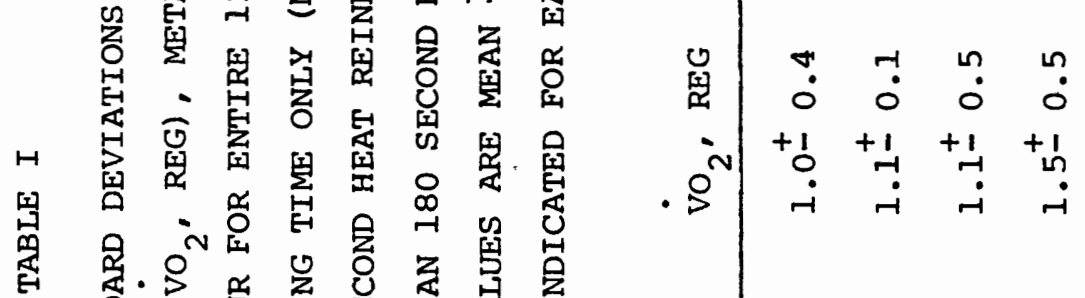

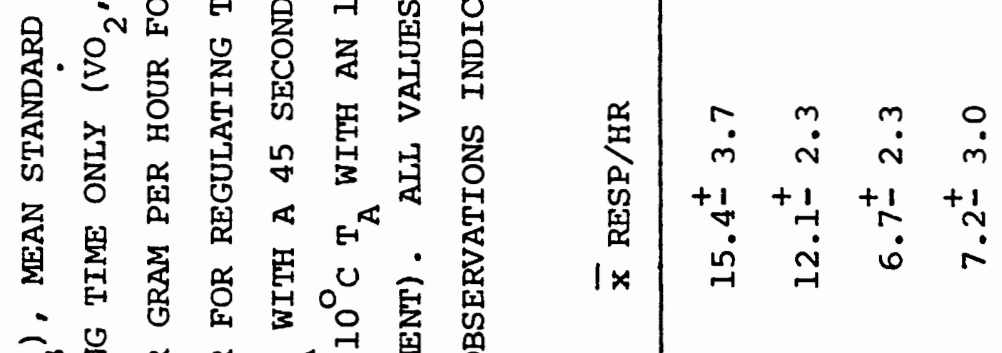

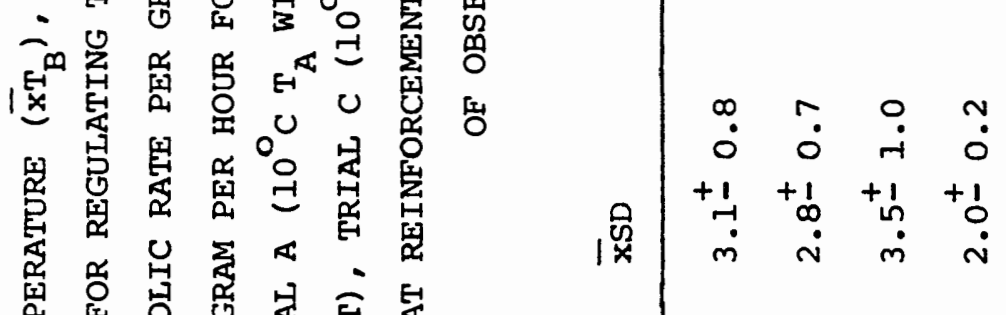

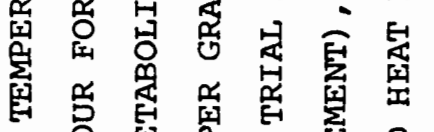

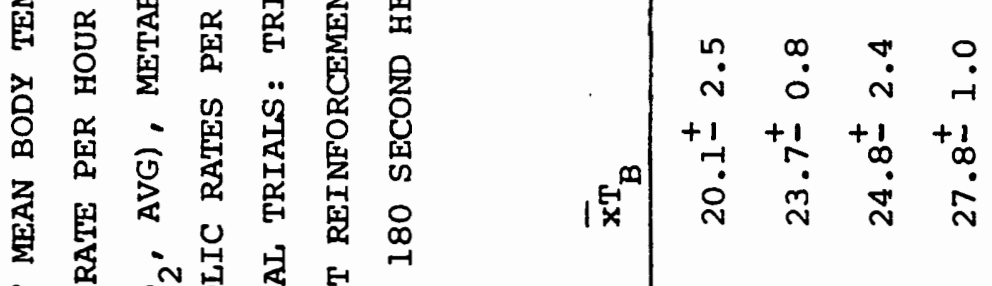

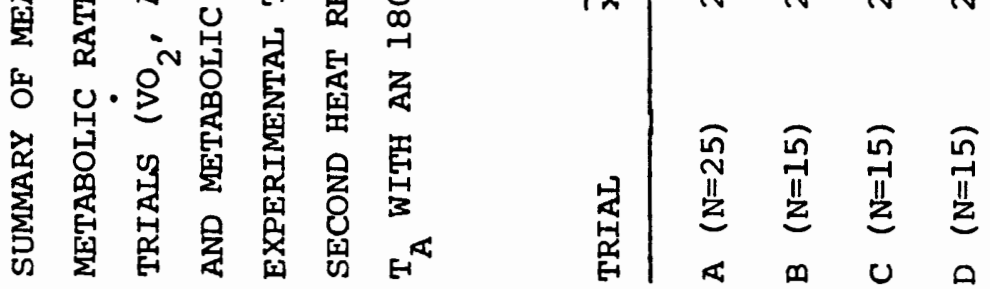


Mean Standard Deviation (

The values for the mean standard deviation for each trial are shown in Table $I(\bar{x} S D)$. The $\overline{x S D}$ for trials $A, B$, and $C$ were not different; similarly the $\overline{x S D}$ for trials $A, B, C$, and $D$ were not significantly different. The $\bar{x} S D$ for trials $C$ and $D$ were significantly different ( $P$.025). These data indicate that the $\bar{x} S D$ is not affected by changes in reinforcement time but is affected by changes in $T_{A}$. $\dot{\mathrm{VO}}_{2}$ While Regulating $\left(\dot{\mathrm{VO}}_{2}, \mathrm{reg}\right)$

The values for $\dot{\mathrm{VO}}_{2}$ while regulating are shown in Table I $\left(\mathrm{VO}_{2}\right.$ ' reg). No significant difference was found in any comparison. Therefore, changes in reinforcement time or changes in $\mathrm{T}_{\mathrm{A}}$ have no effect on $\mathrm{VO}_{2}$, reg. $\dot{\mathrm{VO}}_{2}$ Average $\left(\dot{\mathrm{VO}}_{2}, \mathrm{avg}\right)$

The values for $\mathrm{vo}_{2}$ for each entire $12-\mathrm{hr}$ trial are shown in Table I $\left(\mathrm{VO}_{2}, \mathrm{avg}\right)$. No significant difference was found in any comparison. Therefore, changes in reinforcement time or changes in $\mathrm{T}_{\mathrm{A}}$ have no effect on $\dot{\mathrm{VO}}_{2}$, avg.

Mass Specific $\dot{V O}_{2}$ Average

The values for mean mass specific $\dot{\mathrm{VO}}_{2}$ for each trial are shown in Table I (Mass Specific $\dot{\mathrm{VO}}_{2}, \mathrm{avg}$ ). The mass specific $\dot{\mathrm{VO}}_{2}$, avg for trials A, B, and C were not significantly different; neither were trials $A, B, C$, and $D$. The mass specific $\dot{\mathrm{VO}}_{2}$, avg for trials $\mathrm{C}$ and $\mathrm{D}$ were significantly different $\left(P\right.$.05) . Therefore, mass specific $\dot{\mathrm{VO}}_{2}$ avg was not affected by changes in reinforcement time but was affected by changes is $T_{A}$. 
Mass Specific Vo while Regulating

The values for mass specific $\dot{\mathrm{VO}}_{2}$ while regulating are shown in Table I (Mass Specific $\left.\dot{\mathrm{VO}}_{2}, \mathrm{reg}\right)$. The mass specific $\dot{\mathrm{VO}}_{2}$, reg for trials $A, B$, and $C$ were not significantly different. The mass specific $\dot{\mathrm{VO}}_{2}$, reg for trials $\mathrm{A}, \mathrm{B}, \mathrm{C}$, and $\mathrm{D}$ were significantly different $(P \quad .05)$, as were mass specific $\dot{V O}_{2}$, reg for trials $C$ and $D$ (P .05). Therefore, mass specific $\dot{V O}_{2}$, reg were not affected by changes in reinforcement time but was affected by changes in $\mathrm{T}_{\mathrm{A}}$.

\section{Scaling}

The $R$, intercept and slope values for regression of mass versus mass specific $\dot{\mathrm{VO}}_{2}$, reg are shown in Table II. The slopes in trial $\mathrm{C}$ and $D$ were not significantly different from zero. The $R$ values for trials C and D did not differ significantly. All other values were significant ( $P$.05). The slope in trial $C$ is not significantly different from the expected value of -.25 , the expected norm for mass versus metabolic rate. All other slopes were significantly different from -0.25 . Therefore, it is not possible to predict the metabolic expenditures for thermoregulating lizards of different mass because the scaling relationship varies greatly with environmental factors such as magnitude of reinforcement and $\mathrm{T}_{\mathrm{A}}$. 
TABLE II

SUMMARY OF STATISTICS FOR LEAST SQUARES REGRESSION ANALYSIS OF MASS SPECIFIC OXYGEN CONSUMPTION RATE FOR LIZARDS WHILE REGULATING, AS A FUNCTION OF BODY MASS. N=5 FOR ALL REGRESSIONS. SEE TABLE I FOR

TRIAL LEGEND

TRIAL

A

B

C

D
R VAIUE

0.82

$\left(\begin{array}{ll}P & .025\end{array}\right)$

0.98

(P .05)

0.61

NS

0.37

NS
INTERCEPT

$-1.5 \pm 0.20$

(P .055)

$-0.3 \pm 0.06$

(P .01)

$-1.6 \pm 0.42$

(P .025)

$-1.1 \pm 0.32$

(P .025)
SLOPE

$0.54 \pm 0.22$

(P. .05)

$-0.66 \pm 0.06$

(P. .005)

$0.56 \pm 0.42$

NS

$0.22 \pm 0.32$

NS

$\mathrm{NS}=$ NOT SIGNIFICANT 
CHAPTER IV

\section{DISCUSSION}

All lizards can be considered as obligatory ectotherms (Soule', 1963). Lizards maintain $T_{B}$ well above $T_{A}$ by behavioral means. The level of PBT obtained above $\mathrm{T}_{\mathrm{A}}$ and the precision about that PBT has been used as an index to determine eurythermality and stenothermality in lizards. Variations in $T_{B}$ have been attributed to sex and size differences (Bogert, 1949; Fitch, 1956), environmental factors (Ruibal, 1961; Huey 1974a; Lister, 1976), and cost (Ruibal, 1961; Dewitt, 1967; Regal, 1967; Hertz, 1974; Huey, 1974a; Lister, 1976). Eurythermal lizards were considered to have a wide tolerance to $T_{B}$ fluctuations that had evolved in response to the absence of competition (Ruibal and Philibosian, 1970).

The thermoregulatory behaviors normally associated with purported eurythermic species (i.e., wide $T_{B}$ fluctuations) were absent in this experiment. G. coeruleus was found to be an active and precise regulator of $\mathrm{T}_{B}$.

Feeding schedules were found to be of importance during early baseline studies. G. coeruleus would thermoregulate only for 24 hours after feeding. Therefore, it was necessary to feed the experimental animals the day before each trial.

Under the constraints imposed on the lizards by the physical limitations of the experimental design, three behavioral thermoregu- 
latory strategies were possible:

I. The lizard could adjust the response rate.

II. The lizard could adjust its mean body temperature.

III. The lizard could adjust the amount of time it spends regulating.

These are not mutually exclusive responses. The lizard could adjust one or all of the above in any combination to affect cost of behavioral thermoregulation. The lizard could regulate for varying lengths of time and still achieve the same daily energy expenditures by varying its response rate. For example, a response rate of 10 responses per hour for 12 hours that provides a $\mathrm{T}_{\mathrm{B}}$ of $20^{\circ} \mathrm{C}$ may have the same energy expenditure as a response rate of 20 responses per hour for 6 hours to maintain a $T_{B}$ of $28^{\circ} \mathrm{C}$.

If $\mathrm{G}$. coeruleus maintained its $\mathrm{T}_{B}$ at a constant level, regardless of the metabolic cost (mass specific $\mathrm{VO}_{2}$, reg) then the data should show a similar mean $T_{B}$ between trials for a given individual or for the individuals as a group. An examination of $\mathrm{T}_{\mathrm{B}}$ between the different trials shows a progressive increase in $T_{B}$ between trials $A$ through $D$ with a significant difference in $T_{B}$ between trials. Thus G. coeruleus. under different conditions, appears to regulate to different $T_{B}$. The $T_{B}$ selected would appear to depend upon the costs required (mass specific $\dot{\mathrm{VO}}_{2}$, reg) to maintain that temperature in a given situation.

One way for a lizard to have a lower mean $\mathrm{T}_{\mathrm{B}}$ would be if it regulated less precisely. For example, allowing $\mathrm{T}_{B}$ to periodically approach $\mathrm{T}_{\mathrm{A}}$ in high cost situations (shorter reinforcement times) would 
be reflected by a greater variation in standard deviation of mean $\mathrm{T}_{\mathrm{B}}$ between trials A through $C$. Since standard deviations between trials A through $C$ were not significantly different, differences in precision of thermoregulation does not appear to be a mechanism of lowering mean $\mathrm{T}_{\mathrm{B}} \cdot$

If the mean $\mathrm{T}_{B}$ is an important variable during thermoregulation, then the shuttle rate should increase with a decrease in reinforcement. Shuttle rate was inversely related to reinforcement time during trials A through $C$. However, the increase in shuttle rate at lower reinforcement times was not sufficient to keep the mean $\mathrm{T}_{B}$ constant.

The cost of behavioral thermoregulation (mass specific $\dot{\mathrm{VO}}_{2}$, reg) appears to be an important variable for determining the TB attained since shuttling frequencies between trials $A$ through $C$ were such that the various metabolic costs did not change between these trials. The metabolic cost (mass specific $\dot{\mathrm{VO}}_{2}$, reg) did differ significantly between trials $C$ and $D$ when the ambient temperature was increased from $10^{\circ} \mathrm{C}$ to $20^{\circ} \mathrm{C}$. There was also a significant difference in standard deviation between these two trials, but there is no significant difference in the shuttle rate. G. coeruleus regulated more precisely in trial D than trial $C$ (lower SD) but did not change its shuttle rate; therefore the increase in cost can be attributed to the higher levels of mean temperature $\left(\overline{x T}_{B}\right)$ and the more precise (lower SD) regulation. Both of these changes are the result of a smaller thermal difference between the lizard and its environment at $20^{\circ} \mathrm{C}$ than at $10^{\circ} \mathrm{C}$ (i.e., lizards will gain radiant heat faster and lose heat slower at $20^{\circ} \mathrm{C}$ ). 
Another way $G$. coeruleus could vary metabolic cost (mass specific $\dot{\mathrm{VO}}_{2}$, reg) is to regulate at the same $\mathrm{T}_{\mathrm{B}}$ but for shorter periods of time at lower reinforcement times and lower $\mathrm{T}_{\mathrm{A}}$. There was no significant difference between lizards for trials $A$ through $D$, even though in some cases the largest lizard regulated more than 7 times longer than the smallest.

As the reinforcement periods increase the amount of energy the lizard spends for resting metabolism as compared to the amount of energy expended for shuttling increases. A comparison of resting metabolic cost $\left(\dot{\mathrm{VO}}_{2}\right.$ at $\left.\mathrm{T}_{\mathrm{A}}\right)$, temperature maintenance cost $\left(\dot{\mathrm{VO}}_{2}\right.$ at $\left.\overline{\mathrm{xT}}_{\mathrm{B}}\right)$, and shuttling cost ( $\mathrm{VO}_{2}$ per meter times shuttle rate) shows that the cost of shuttling is the major cost component during trial $A$, the cost of shuttling and maintaining $\overline{x T}_{B}$ are about equal during trial $B$, and the cost of maintaining temperature $\left(\overline{x T}_{B}\right)$ during trials $C$ and $D$ were the major costs. The total metabolic costs during trials A, B, and C $\dot{\mathrm{VO}}_{2}$, reg) were not significantly different. The larger metabolic expenditure during trial $D$ is due to the larger resting metabolic cost $\left(\mathrm{VO}_{2}\right.$ at $\left.\mathrm{T}_{\mathrm{A}}\right)$. These changing metabolic cost components are reflected in Figure 1.

G. coeruleus has been described in the literature as a diurnal nonbasking, eurythermic species with a wide range of mean $T_{B}$ (Brattstrom, 1965). Their reported eurythermality is assumed to be the consequence of living in an environment where the cost of behavioral thermoregulation to within narrow limits in a stenothermic manner would greatly outweigh the benefits in a physiological sense (Huey, 1974a). Eurythermality can be examined in two different contexts. If a 


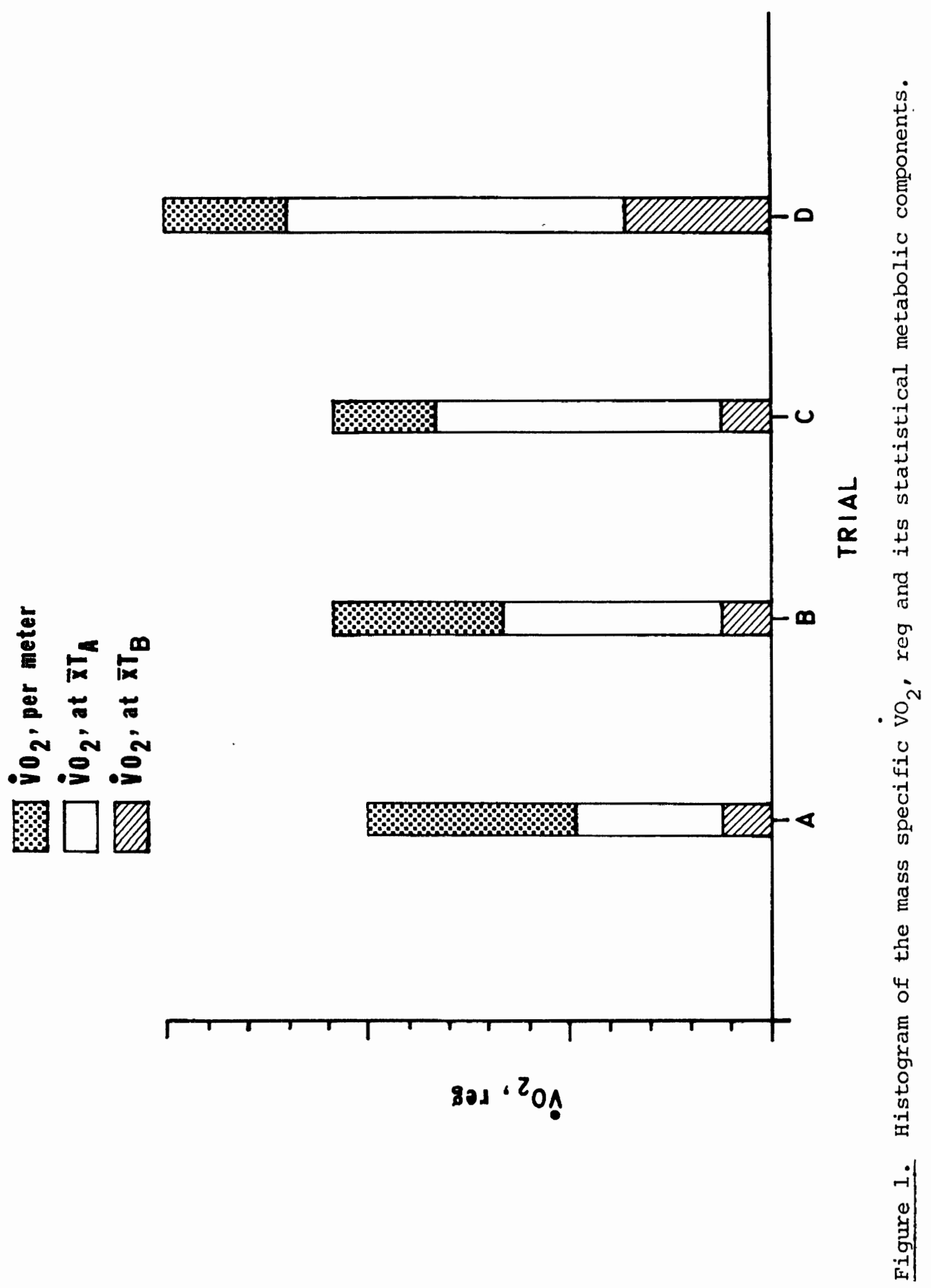


lizard is to be considered eurythermal in the classical sense, then the levels of mean $T_{B}$ realized should be of no consequence to the animals as long as these $\mathrm{T}_{\mathrm{B}}$ fall within the lizards normal activity range (i.e., above critical thermal minimum and below critical thermal maximum). There should also be a wide variation in realized metabolic cost in various environmental situations. The only metabolic costs associated with thermoregulation in such a lizard, in this situation, would be shuttling costs required to avoid critical minima and maxima. Brattstrom's (1965) field data for $T_{B}$ of $G$. coeruleus seem to indicate that this lizard is eurythermal, because it has a range ot $T_{B}$ from $11.0^{\circ} \mathrm{C}$ to $19.4^{\circ} \mathrm{C}$ with a mean $\mathrm{T}_{\mathrm{B}}$ of $15.8^{\circ} \mathrm{C} . \mathrm{G}$. coeruleus in a no-cost thermal gradient in the laboratory will select a $T_{B}$ of around 29 to $31^{\circ} \mathrm{C}$ (Campbell, personal observation). The implication has always been that this difference in PBT between field and lab indicates the species can exist equally well at both temperature extremes.

A second way to view eurythermality is to assume that the lizard would have a temperature preference range as narrow as a traditional stenothermic lizard (Dipsosaurus dorsalis) if the metabolic costs of maintaining this narrow range were low. This has already been shown to some degree by the higher preferred body temperatures of eurythermic lizards in laboratory thermogradients where the metabolic cost of thermoregulation has only a resting metabolic component with no shuttling costs involved.

These data indicate that eurythermality of $G$. coeruleus is caused by fluctuations in preferred $\mathrm{T}_{\mathrm{B}}$ and not precision around this temperature. Eurythermality is also associated with changes in the 
metabolic cost of shuttling and the metabolic cost of maintaining higher $\mathrm{T}_{\mathrm{B}}$.

When G. coeruleus is presented with shorter reinforcement times it responds by shuttling more frequently, but at a lower mean $T_{B}$. The importance of this observation is that the metabolic cost of behavioral thermoregulation does not change with a corresponding change in reinforcement time at any given $\mathrm{T}_{\mathrm{A}^{\prime}}$, but the mean $\mathrm{T}_{\mathrm{B}}$ and shuttle rate do change.

In these experiments $G$. coeruleus regulated precisely around a selected $\mathrm{T}_{\mathrm{B}}$ in all experiments, or did not regulate at all. In over 1000 hours of detailed observation the mean deviation from selected $\mathrm{T}_{\mathrm{B}}$ was only $\pm 2.8^{\circ} \mathrm{C}$ with a range of $1.7^{\circ} \mathrm{C}$ to $4.8^{\circ} \mathrm{C}$. Statistically the deviation from the mean $\mathrm{T}_{\mathrm{B}}$ did not change during the $10^{\circ} \mathrm{C}$ trials (trials A through C). At any given trial any individual lizard should be considered to be stenothermic in that it had a narrow range of $T_{B}$ around a selected mean $T_{B}$. It is only in the examination of the mean selected $\mathrm{T}_{\mathrm{B}}$ of all lizards examined together for all the trials that eurythermality was exhibited. This supports the findings of Huey and Stevenson (1979) that examination of data for populations as a whole may indicate a broad optimal temperature range when instead individual members of that population are regulating precisely.

At longer reinforcement times or higher $\mathrm{T}_{\mathrm{A}}$ trials the metabolic costs of thermoregulation remained the same when compared to all trials. Any drop in the metabolic cost of shuttling was counterbalanced by the increase in the resting metabolism of the higher mean $T_{B}$ realized at higher reinforcements. 
These experiments indicate that $\underline{G}$. coeruleus must derive some benefit from short term stenothermic behavior. This lizard still precisely regulated to a mean $T_{B}$ of $27.8^{\circ} \mathrm{C} \pm 1^{\circ} \mathrm{C}$ during trial $\mathrm{D}$, when the $\mathrm{T}_{\mathrm{A}}\left(20^{\circ} \mathrm{C}\right)$ was higher than the mean $\mathrm{T}_{\mathrm{B}}$ recorded for this species in the field $\left(15.8^{\circ} \mathrm{C}\right)$ and higher than the recorded upper limit of its normal activity range $\left(19.8^{\circ} \mathrm{C}\right)$. If the lizards had shuttled during trial $\mathrm{C}$ with the frequency that they shuttled during trial $\mathrm{B}$ (16.2 resp/hr at trial B as compared to $11.5 \mathrm{resp} / \mathrm{hr}$ at trial C) then they could have easily regulated to $27.8^{\circ} \mathrm{C}$ during trial $\mathrm{C}$ as well as trial D. That this did not occur may indicate that the metabolic cost of shuttling was the limiting factor and that the lizards gained some advantage at $a \mathrm{~T}_{\mathrm{B}}$ of $24.4^{\circ} \mathrm{C}$ (trial $\mathrm{C}$ ) as well as at a $\mathrm{T}_{\mathrm{B}}$ of $27.8^{\circ} \mathrm{C}$ (trial D).

These results imply that the wide range of $\mathrm{T}_{\mathrm{B}}$ recorded for G. coeruleus in the field may be measurements of different lizards regulating stenothermically to their own individual mean $T_{B}$ rather than just random $T_{B}$ associated with a normal activity range, or they are not regulating at all $\left(T_{B}=T_{A}\right)$. A calculation of the mean $T_{B}$ for all lizards during all hours of the 12-hr trials (regulating temperatures and resting temperatures $\left(T_{B}+T_{A}\right)$ in these experiments shows that using the typical field methods employed in Brattstrom (1965) the mean $\mathrm{T}_{\mathrm{B}}$ of these lizards during these experiments would be $17.8^{\circ} \mathrm{C}$. In fact, during periods of active behavioral thermoregulation, $T_{B}$ consistently this low were only recorded twice during the entire experiment and those two recordings took place in trial $A$ when the reinforcement period and $\mathrm{T}_{\mathrm{A}}$ were at their lowest. 
G. coeruleus either regulates $T_{B}$ for short stenothermic periods (7-8 hours average) or does not regulate at all. In a complex field environment where many microenvironments exist and the cost associated with behavioral thermoregulation varies widely from location to location, or day to day, the $T_{B}$ of $\underline{G}$. coeruleus will show wide variations. However, these variations are not the recorded effect of lizards operating a wide normal activity range but the recorded effect. of lizards regulating close to a mean $\mathrm{T}_{\mathrm{B}}$ that is dictated by the metabolic eost associated with the environment at that time.

Patterns of eurythermy and stenothermy may be determined as much by the environment in which the animal lives as by evolutionary, physiological, or behavioral considerations. It is possible that purported eurytheraml species would thermoregulate with the same precision and for equal lengths of time as stenothermic species if they are presented with the same uniform low cost environments within the limits of their critical thermal temperatures. This idea is supported by these experiments where $G$. coeruleus thermoregulates around high $\mathrm{T}_{\mathrm{B}}\left(27.8^{\circ} \mathrm{C} \pm 1.0^{\circ} \mathrm{C}\right)$ as precisely as Dipsosaurus dorsalis does $\left(42.4^{\circ} \mathrm{C} \pm 1.8^{\circ} \mathrm{C}\right.$ (Norris, 1953)), but at lower temperature values. Similarly, purported stenothermic lizards in high cost environments would decrease their PBT. Therefore, evolutionary interpretations (Huey, 1974a) of purported eurythermal species by be premature.

\section{SCAIING}

The mass specific $\dot{\mathrm{V}}_{2}$, reg expressed in these experiments is the sum of metabolic rates of shuttling ( $\dot{\mathrm{VO}}_{2}$ per gram meter) and the 
constant $\mathrm{T}_{\mathrm{B}}$ energy requirements $\left(\dot{\mathrm{VO}}_{2}\right.$ at $\left.\overline{\mathrm{x}} \mathrm{T}_{\mathrm{B}}\right)$ combined in various combinations to reflect the total energy dynamics of a fluctuating thermoregulatory system. Shuttling rates and the metabolic cost of being at constant $T_{B}$ do not change in direct proportion to one another. The effect of reinforcement length $(45$ seconds, 90 seconds, or 180 seconds) and $T_{A}$ changes $\left(10^{\circ} \mathrm{C}\right.$ and $20^{\circ} \mathrm{C}$ ) on the relationship between mass specific $\dot{\mathrm{VO}}_{2}$, reg and mass is illustrated in Figure 2.

The reinforcement period of 45 seconds at a $T_{A}$ of $10^{\circ} \mathrm{C}$, during trial A, was not sufficient to allow the smallest lizard $(6.6 \mathrm{~g})$ to maintain a $T_{B}$ as high as the largest lizard. The largest lizard (14.4 g), however, maintained a constant $\mathrm{T}_{\mathrm{B}}\left(23.3^{ \pm} 2.3^{\circ} \mathrm{C}\right)$ by shuttling at a greater rate $(19.5 \mathrm{resp} / \mathrm{hr})$. The three intermediate-sized lizards had slightly lower shuttle rates $(16 \mathrm{resp} / \mathrm{hr})$. Therefore, their total metabolic expenditure (mass specific $\dot{\mathrm{VO}}_{2}$, reg) per gram was midway between the largest and smallest lizard.

The reinforcement period of 90 seconds at $\mathrm{T}_{\mathrm{A}} 10^{\circ} \mathrm{C}$, during trial $B$, was sufficient to allow the smallest lizard to maintain a $\mathrm{T}_{\mathrm{B}}$ slightly higher than the $\mathrm{T}_{\mathrm{B}}$ reached by the larger lizard during trial $\mathrm{A}$, but only at a much higher response rate $(14.2$ resp/hr for the small lizard versus $9.1 \mathrm{resp} / \mathrm{hr}$ for the large lizard). This resulted in greater energetic expenditures per gram (mass specific $\dot{\mathrm{VO}}_{2}$, reg) for the smaller lizard. The intermediate-sized lizards shuttled less frequently to a slightly higher temperature than trial $A$ and therefore had the same total metabolic expenditures per gram (mass specific $\dot{\mathrm{VO}}_{2}$, reg) during trial $\mathrm{B}$ as they did in trial $A$.

The reinforcement period was extended to 180 seconds at $10^{\circ} \mathrm{C}$, 


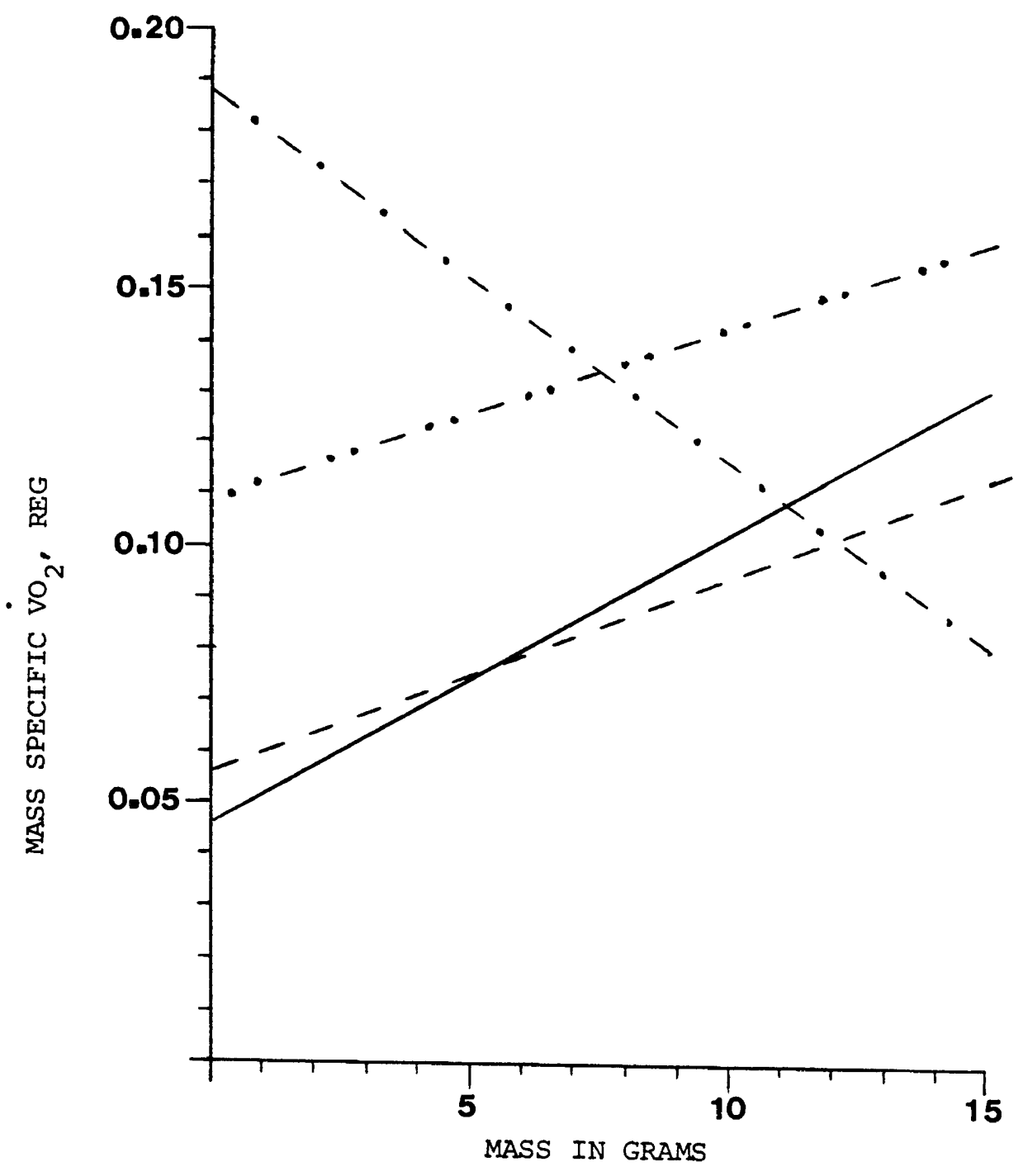

Figure 2. Graph of mass specific $\dot{\mathrm{VO}}_{2}$, reg versus mass for all trials

$--\quad=45$ seconds (trial A)

- - - = 90 seconds (trial B)

$\longrightarrow=180$ seconds (trial C) $10^{\circ} \mathrm{C}$

$-\cdots-=180$ seconds (trial D) $20^{\circ} \mathrm{C}$ 
during trial $\mathrm{C}$. The smaller lizard regulated in this situation to a lower $T_{B}$ than the other lizards with a correspondingly lower shuttle rate. The largest lizard regulated $\mathrm{T}_{B}$ to a temperature higher than the other lizards with a correspondingly higher shuttle rate.

All the lizards thermoregulated to a slightly higher temperature during trial D, than trial $C$, but maintained the same shuttle rate.

The main fluctuations in metabolic cost per gram (mass specific $\dot{\mathrm{VO}}_{2}$, reg) between trials was due to the differences between the largest and smallest lizard (Figure 2).

The largest metabolic expenditure during trial A was the cost of shuttling $\left(\dot{\mathrm{VO}}_{2}\right.$ per gram meter). The costs of shuttling and maintenance of temperature $\left(\dot{\mathrm{VO}}_{2}\right.$ at $\left.\overline{\mathrm{xT}}_{\mathrm{B}}\right)$ were about equal during trial $\mathrm{B}$. The cost of having a high $\mathrm{T}_{B}$ was the largest metabolic expenditure during trials $C$ and $D$. The total metabolic expenditures (mass specific $\dot{\mathrm{VO}}_{2}{ }^{\prime}$ reg) during trial $\mathrm{D}$ were larger than during trial $\mathrm{C}$ because of the greater metabolic cost $\left(\dot{\mathrm{VO}}_{2}\right.$ at $\left.\overline{\mathrm{XT}}_{\mathrm{B}}\right)$ at $20^{\circ} \mathrm{C}$ as compared to $10^{\circ} \mathrm{C}$, and a slightly higher body temperature (see Table I). These variations are illustrated in Figure $I$. 
Bakker, R.T. 1972. "Locomotor energetics of lizards and mammals compared," Physiologist 15: 278.

Ballinger, R.E., J. Hawker and O.J. Sexton 1969. "The effect of photoperiod acclimation on the thermoregulation of the lizard Sceloporus undulatus," J. Exp. Zool. 171: 43-48.

Barber, B.J. and E.C. Crawford Jr. 1976. "A stochastic dual-limit hypothesis for behavioral thermoregulation in lizards," Physiol. Zool. 50: 53-60.

Barber, B.J. and E.C. Crawford Jr. 1978. "Dual threshold control of peripheral temperature in the lizard Dipsosaurus dorsalis," Physiol. Zool. 52: 250-263.

Bartholomew, G.A. 1966. "A field study of temperature relations in the Galapagos Marine Iguana," Copeia 2: 24l-250.

Bartholomew, G.A. and V.A. Tucker 1963. "Control of changes in body temperature, metabolism, and circulation by the agamid lizard Amphibolorus barbatus," Physiol. Zool. 36: 199-218.

Bartlett, P.N. and D.M. Gates 1967. "The energy budget of a lizard on a tree trunk," Ecology 48: 315-322.

Berk, M.L. and J.E. Heath 1975. "An analysis of behavioral thermoregulation in the lizard, Dipsosaurus dorsalis," Journal of Thermal Biology 1: 15-22.

Bogert, C.M. 1949. "Thermoregulation in reptiles, a factor in evolution," Evolution, Vol III, 3: 195-211.

Brattstrom, B.H. 1965. "Body temperatures of reptiles," Amer, Midland Natur. $73: 376-422$.

Burghardt, G.M. 1977. "Learning processes in reptiles." In "Biology of the reptillia," edited by Carl Gans. Academic Press, New York pp 555-681.

Carlisle, H.J. 1969. "Effect of fixed-ratio thermal reinforcement on thermoregulatory behavior," Physiology and Behavior, Vol. 4, pp 23-28. 
Case, T. 1972. "Thermoregulation and evaporative cooling in the chuckwalla, Sauromalus obesus," Copeia 1: 145-150.

Crawford, F.T., P.M. Adams and J.M. Whitt 1968. "Response rate of turtles to fixed ratio reinforcements," Psychon. Sci. Vol. 6 1: $19-20$.

Dawson, С.B. 1967. "On the physiological significance of the preferred body temperature of reptiles." In D.M. Gates and R.B. Schmerl (eds) Perspectives of biophysical ecology, Ecological studies, Vol. 12: 443-473. Springer-Verlag, N.Y.

DeWitt, C.B. 1967. "Precision of thermoregulation and its relation to environmental factors in the desert iguana Dipsosaurus dorsalis. Physiol. Zool 40: 49-66.

DeWitt, C.B. 1971. "Postural mechanisms in the behavioral thermoregulation of a desert lizard Dipsosaurus dorsalis," J. Physiol. (Paris) 63: 242-245.

Dmi'el, R. and D. Rappeport 1976. "Effect of temperature on metabolism during running in the lizard Uromastix aegyptios," Physiol. Zool. Vol. 49, 1: 77-84.

Fitch, H.S. 1956. "An ecological study of the collared lizard (Crotaphytus collaris)," Univ. Kans. Publ. Mus. Nat. Hist. 8: 213-274.

Gleeson, T.T. 1979. "The effects of training and captivity on the metabolic capacity of the lizard Sceloporus occidentalis," J. Comp Physiol. B. 129: 123-128.

Hammel, H.T., F.T. Caldwell, and R.M. Abrams 1967. "Regulation of body temperatures in the Blue Tongued Lizard," Science 156: 1260-1262.

Heath, J.E. 1964. "Head-body temperature differences in horned lizards," Physiol. Zoo1. 37: 273-279.

Heath, J.E. 1965. "Temperature regulation and diurnal activity in horned lizards," Univ. Calif. Publ. Zool. 64: 97-136.

Heatwole, J., T.H. Lin, E. Villalon, A. Muntz and A. Matta 1969. "Some aspects of the thermal ecology of Puerto Rican Anoline lizards," J. Herpetol. 3: 65-77.

Hertz, P.E. 1974. "Thermal passivity to a tropical lizard, Anolis'polylipis," J. Herpetol. 8: 323-327. 
Hoffman, M. 1973. "Locomotor activity, body temperature and metabolic scope in the Southern Alligator Lizard, Gerrhonotus multicarinatus webbi (Anguidae)," Unpublished Masters Thesis, Calif. State Univ. Fullerton, Calif.

Huey, R.B. 1974a. "Behavioral thermoregulation in lizards; importance of associated cost," Science 184: 1001-1003.

Huey, R.B. 1974b. "Winter thermal ecology of the iguanid lizard Tropidurus peruvianus," Copeia 149-155.

Huey, R.B. and M. Slatkin 1976. "Cost and benefits of lizard thermoregulation," The Quarterly Review of Biology 51: 363-384.

Huey, R.B. and R.D. Stevenson 1979. "Integrating thermal physiology and ecology of ectotherms: A discussion of approaches," Amer. Zool. 19: 357-366.

Huey, R.B. and T.P. Webster 1975. "Thermal biology of a solitary lizard: Anolis marmoratus of Guadeloupe, Lesser Antilles," Ecology 56:445-452.

Kellogg, W.N. and W.B. Pomeroy 1936. "Maze learning in water snakes," J. Comp Psych. Vo1. 21, 3: 275-295.

Kemp, F.D. 1969. "Thermal reinforcement and thermoregulatory behavior in the lizard Dipsosaurus dorsalis: An operant technique," Anim. Behav. 17: 446-451.

Lee, J.C. 1980. "Comparative thermal ecology of two lizards," Oecologia (Ber1) 44: 171-176.

Linton, S.J. 1976. "Behavioral thermoregulation in the Spectacled Caiman (Caiman sclerops)," Beh. Res. Methods \& Inst. Vol. 8, 5: 479-480.

Lister, B.C. 1976. "The nature of niche expansion in West Indian Anolid lizards: Ecological consequences of reduced competition," Evolution 30: 659-676.

Morgareidge, K.R. and F.N. White 1969. "Cutaneous vascular changes during heating and cooling in the Galapagos Marine Iguana," Nature Lond. 223: 587-599.

Muth, A. 1977. "Thermoregulatory postures and orientation to the sun: A mechanistic evaluation for the Zebra-tailed lizard, Callisaurus draconoides," Copeia 4: 710-719.

Norris, K.S. 1948. "Arboreal feeding habits and feeding of the gridiron tailed lizard," Herpetologica 4: 217-218. 
Norris, K.S. 1953. "The ecology of the Desert Iguana Dipsosaurus dorsalis," Ecology 34: 265-287.

Planka, E.R. and W.S. Parker 1972. "Ecology of the iguanid lizard Callisaurus draconoides," Copeia 1972: 493-508.

Porter, W.P., J.W. Mitche11, W.A. Beckman, and C.B. DeWitt 1973. "Behavioral implications of mechanistic ecology - thermal and behavioral, modeling of desert ectotherms and their environment. Decologia 13: 1-54.

Regal, P.J. 1966. "Thermophilic responses following feeding in certain reptiles," Copeia 3: 588-590.

Regal, P.J. 1967. "Voluntary hypothermia in reptiles," Science 155: 1551-1553.

Regal, P.J. 1971. "Long term studies with operant conditioning techniques, of temperature regulation patterns in reptiles," Journal de Physiologie 63: 403-406.

Richardson, A.M. and M.R. Brown 1975. "Thermoregulation operant behavior in the Desert Iguana Dipsosaurus dorsalis," Herp. Rev. $6: 72-73$.

Richardson, A.M. and M.R. Brown 1976. "Thermoregulation operant behavior in the Collared Lizard Crotaphytus collaris," Paper presented at the meeting of the Western Psychological Association, Los Angeles, April 1976.

Rozin, P.N. and J. Mayer 1961. "Thermal reinforcement and thermoregulatory behavior in the goldfish, Carassius auratus," Science 134: 942-943.

Ruibal, R. 1961. "Thermal relations of five species of tropical lizards," Evolution 15: 98-111.

Ruibal, R. and R. Philibosian 1970. "Eurythermy and niche expansion in lizards," Copeia 1970: 645-653.

Schmidt-Nielsen, K. 1972. "How animals work," Cambridge University Press, New York.

Schmidt-Nielsen, K. and W.R. Dawson 1964. "Terrestrial animals in dry heat: desert reptiles." In Handbood of physiology, Section 4: Adaption to the environment. Amer. Physiol. Soc. Washington, D.C. pp $467-480$.

Snedecor, G.W. 1956. "Statistical methods applied to experiments in agriculture and biology," The Iowa State College Press, Ames, Iowa. 
Soule', M. 1963. "Aspects of thermoregulation in nine species of lizards from Baja, California," Copeia 1: 107-115.

Spellerburg, I.F. 1972. "Thermal ecology of allopatric 11zards (Sphenomorphus) in Southeast Australia, III, Behavioral aspects of thermoregulation," Decologia 11: 1-16.

Stebbins, R.C. 1966. "A field guide to Western reptiles and amphibians," Houghton Mifflin Company, Boston pp 106-107.

Vitt, L.J. 1974. "Body temperatures of high latitude reptiles," Copeia 1: 255-256.

Weathers, W.W. 1970. "Physiological thermoregulation in the lizard Dipsosaurus dorsalis," Copeia 3: 549-557.

Weathers, W.W. 1971. "Some cardiovascular aspects of temperature regulation in the lizard Dipsosaurus dorsalis," Comp. Biochem. Physiol. 40A: 503-515.

Weiss, B. and V.G. Laties 1960. "Magnitude of reinforcement as a variable in thermor egulatory behavior," J. Comp. Physiol. and Psych. Vol. 53, 6: 603-608.

White, F.N. 1973. "Temperature and the Galapagos Marine Iguana Insights into reptilian thermoregulation," Comp. Biochem. Physiol. 45A: 503-513. 